Published in final edited form as:

Cancer Res. 2011 December 15; 71(24): 7463-7470. doi:10.1158/0008-5472.CAN-11-2449.

\title{
PGE $_{2}$-Induced CXCL12 Production and CXCR4 Expression Controls the Accumulation of Human MDSCs in Ovarian Cancer Environment
}

\author{
Nataša Obermajer ${ }^{1}$, Ravikumar Muthuswamy ${ }^{1}$, Kunle Odunsi ${ }^{7}$, Robert P. Edwards ${ }^{4,5,6}$, and \\ Pawel Kalinski ${ }^{1,2,3,4}$ \\ ${ }^{1}$ Department of Surgery, University of Pittsburgh, Pittsburgh, Pennsylvania \\ ${ }^{2}$ Department of Immunology, University of Pittsburgh, Pittsburgh, Pennsylvania \\ ${ }^{3}$ Infectious Diseases and Microbiology, University of Pittsburgh, Pittsburgh, Pennsylvania \\ ${ }^{4}$ University of Pittsburgh Cancer Institute, University of Pittsburgh, Pittsburgh, Pennsylvania \\ ${ }^{5}$ Peritoneal/Ovarian Cancer Specialty Care Center, Hillman Cancer Center, University of \\ Pittsburgh, Pittsburgh, Pennsylvania \\ ${ }^{6}$ Magee-Womens Research Institute Ovarian Cancer Center of Excellence, University of \\ Pittsburgh, Pittsburgh, Pennsylvania \\ ${ }^{7}$ Department of Gynecologic Oncology and Immunology, Roswell Park Cancer Institute, Buffalo, \\ New York
}

\begin{abstract}
Signals mediated by CXCL12 (SDF1) and its receptor CXCR4 are centrally involved in cancer progression, both directly by activating cancer cells and indirectly by inducing angiogenesis plus recruiting $\mathrm{T}$ regulatory and plasmacytoid dendritic immune cells. Here, we show that in ascites isolated from ovarian cancer patients, both CXCL12 and CXCR4 are controlled by the tumorassociated inflammatory mediator prostaglandin $\mathrm{E}_{2}\left(\mathrm{PGE}_{2}\right)$, which attracts myeloid-derived suppressor cells (MDSC) into the ascites microenvironment. In this setting, $\mathrm{PGE}_{2}$ was essential both for expression of functional CXCR4 in cancer-associated MDSCs and for production of its ligand CXCL12. Frequencies of CD11 b ${ }^{+} \mathrm{CD} 14^{+} \mathrm{CD} 33^{+} \mathrm{CXCR} 4^{+}$MDSCs closely correlated with CXCL12 and $\mathrm{PGE}_{2}$ levels in patient ascites. MDSCs migrated toward ovarian cancer ascites in a CXCR4-dependent manner that required $\mathrm{COX} 2$ activity and autocrine $\mathrm{PGE}_{2}$ production. Inhibition of COX2 or the $\mathrm{PGE}_{2}$ receptors EP2/EP4 in MDSCs suppressed expression of CXCR4 and MDSC responsiveness to CXCL12 or ovarian cancer ascites. Similarly, COX2 inhibition also blocked CXCL12 production in the ovarian cancer environment and its ability to attract MDSCs. Together, our findings elucidate a central role for $\mathrm{PGE}_{2}$ in MDSC accumulation triggered by the CXCL12-
\end{abstract}

Corresponding Author: Pawel Kalinski, Department of Surgery, Hillman Cancer Center, University of Pittsburgh, UPCI Research Pavilion, Room 1.46, 5117 Center Avenue, Pittsburgh, PA 15213. Phone: 412-623-7712; Fax: 412-623-7709; kalinskip@ upmc.edu.

Disclosure of Potential Conflicts of Interest

No potential conflicts of interest were disclosed. 
CXCR4 pathway, providing a powerful rationale to target $\mathrm{PGE}_{2}$ signaling in ovarian cancer therapy.

\section{Introduction}

Stromal cell-derived factor-1 (SDF-1, now designated as CXCL12) is overproduced by stromal and tumor cells in different tumor microenvironments (1-4). CXCL12 exerts multiple tumor-promoting functions, either directly through its cognate receptor CXCR4 present on cancer cells enhancing tumor growth, migration, and invasiveness, or indirectly by recruiting endothelial progenitors, needed for tumor angiogenesis $(3,5,6)$. Moreover, regulatory $\mathrm{T}$ cells $\left(\mathrm{T}_{\text {reg }}\right)$ and plasmacytoid dendritic cells $(\mathrm{pDC})$, which play a crucial role in immune evasion, are attracted to the tumor environment through CXCL12 (6-8). By recruiting and retaining these immunosuppressive cells, the tumor microenvironment limits the effectiveness of immune responses (9).

Myeloid-derived suppressor cells (MDSC; ref. 10,11) have emerged as critical elements of cancer-induced immune dysfunction. MDSCs carry out their suppressive functions at the site of tumor growth (10) and represent a heterogeneous population of immature myeloid cells involving immature precursors of macrophages, granulocytes, and dendritic cells (DC), capable of suppressing immune response in vitro and in vivo (12). MDSCs residing within the tumor environment are deficient in costimulatory-molecule expression, and inefficient in lymphoid homing (13). Instead, they abrogate adaptive immune responses to cancer cells, as shown in experimental animal models and human cancer patients (14).

High activity of the ovarian cancer microenvironment to attract other types of suppressive cells (6-8) suggests that, in addition to accelerated development of MDSCs in cancer setting, the predominance of MDSCs in ovarian cancer microenvironment may result from their enhanced attraction and/or retention. Although the molecular mechanisms that regulate the development and function of MDSCs in the cancer setting have been extensively studied, particularly in the mouse system $(13,15-21)$, the mechanisms guiding MDSCs to human cancer environments remain poorly understood.

Guided by prior mouse studies showing the involvement of $\mathrm{PGE}_{2}$ in the regulation of CXCL12 production in cancer-associated fibroblasts (22), and the ability of $\mathrm{PGE}_{2}$-producing tumor cells to enhance CXCR4 expression on differentiating mouse MDSCs (23, 24), we tested the relevance of $\mathrm{PGE}_{2}$ in the regulation of the CXCR4-CXCL12 interplay in human ovarian cancer-infiltrating MDSCs. Our data show that the CXCR4-CXCL12 axis is the key pathway mediating the attraction of monocytic MDSC into the tumor environment of ovarian cancer patients, with $\mathrm{PGE}_{2}$ responsible for the induction of both functional CXCR4 and CXCL12. The ability of COX2 inhibitors and $\mathrm{PGE}_{2}$ receptor blockers to reverse the chemokine responsiveness of fully developed MDSCs and to decrease the levels of CXCL12 produced in the ovarian cancer environment provides a new tool to counteract immune suppression in therapeutic regimens aimed at restoring immune surveillance in cancer patients. 


\section{Materials and Methods}

\section{Patients}

Human ovarian cancer ascites and sera were obtained from previously untreated patients with advanced epithelial ovarian cancer in stage III or IV, after obtaining written informed consent. The nature and possible consequences of the studies were explained. All specimens were provided under the protocols approved by the University of Pittsburgh Institutional Review Board (IRB0406147) or the Roswell Park Cancer Institute Institutional Review Board (CIC02-15). Patients underwent a primary surgical debulking procedure for clinical staging. Fresh ascites were obtained intraoperatively, and blood draws were done either immediately preoperatively or at the first postoperative visit prior to any adjuvant therapy.

\section{Isolation of ovarian cancer ascites-infiltrating cells and MDSCs}

Human ovarian cancer ascites were collected aseptically and infiltrating primary cells harvested by centrifugation. CD11 $\mathrm{b}^{+}$MDSCs were obtained after centrifugation of ascites, followed by RBC lysis and positive magnetic selection of CD11 $\mathrm{b}^{+}$cells (CD11b EasySep Isolation kit; Stem Cell Tech). The isolated cells were CD11b ${ }^{+}>95 \%$ pure. Control CD11 $b^{+}$ cells were isolated from healthy donor buffy coats, using the same method.

\section{Flow cytometry}

Two- and 3-color cell surface and intracellular immunostaining analysis was done using Beckman Coulter Epics XL or Accuri flow-cytometer. Ovarian cancer-isolated cells were stained with the following antibodies CCR2-PE, CCR5-PE, CCR6-PE, CXCR1-PE, CXCR4-PE, CD11b-FITC, CD14-PE, CD33-APC, CD34-PE/Cy7 (BD and eBioscience). Rat IgG2a-PE, IgG1-FITC, IgG1-APC, and IgG1-PE/Cy7 isotype controls, and rat IgG2aFITC isotype control were from BD PharMingen.

\section{Chemotaxis assay}

Chemotaxis assays were done as previously described (25). rhu-CXCL-12a $(5-50 \mathrm{ng} / \mathrm{mL}$; $\mathrm{R} \& \mathrm{D})$ in IMDM+0.5\% FBS or ovarian cancer ascites were used as chemotaxis media. When indicated, cells were pretreated for 10 minutes with CXCR4 antagonist AMD3100 (1,000 $\mathrm{ng} / \mathrm{mL}$; Sigma) and CCR5 antagonist vicriviroc $(1,000 \mathrm{ng} / \mathrm{mL})$ before chemotaxis experiments to block the CXCR4 and CCR5-dependent chemotaxis. For desensitization, CXCL12 or CCL5 were added to the cells in the upper chamber 10 minutes before the chemotaxis experiment. The concentrations of the blocking agents used did not have any significant impact on the viability of cultured cells, as determined by the live cell counts.

\section{Isolation of peripheral blood naive CD8 ${ }^{+} \mathrm{T}$-cell populations and CD3/CD28 in vitro effector generation}

Naive $\mathrm{CD}^{+} \mathrm{CD} 45 \mathrm{RA}^{+} \mathrm{CD} 45 \mathrm{RO}^{-} \mathrm{T}$ cells were isolated from PBMCs by negative selection using the naive $\mathrm{CD}^{+} \mathrm{T}$-cell enrichment cocktail (Stem Cell Tech), resulting in a uniform population of $\mathrm{CD}^{+}{ }^{+} \mathrm{CD} 45 \mathrm{RA}^{+} \mathrm{CD} 45 \mathrm{RO}^{-}$cells. $\mathrm{CD} 8^{+} \mathrm{T}$ cells were stimulated with $\mathrm{CD} 3 /$ CD28 Dynabeads ( $5 \mu \mathrm{L} / \mathrm{mL}$; Invitrogen Dynal AS) in the presence or absence of ovarian cancer ascites-isolated MDSCs. CFSE staining of $\mathrm{CD} 8^{+} \mathrm{T}$ cells (Invitrogen) was done 
according to the manufacturer's instructions. On day 4 and 5, expanded $\mathrm{CD} 8^{+} \mathrm{T}$ cells were analyzed for the expression of granzyme B expression and proliferation.

\section{ELISA}

Ovarian cancer ascites were collected into collection tubes, centrifuged at 2,000 rpm for 10 minutes and the supernatants were immediately stored at $-80^{\circ} \mathrm{C}$ until use. Ovarian cancer ascites were used immediately after defrosting and were not subjected to further freeze-thaw cycles. Ovarian cancer ascites and conditioned media generated by culturing ovarian cancer ascites-infiltrating primary cells for 48 hours were analyzed for CXCL12/SDF-1 and CCL5 by indirect sandwich ELISA (R\&D) and $\mathrm{PGE}_{2}$ by competitive parameter immunoassay according to the manufacturer's protocol (R\&D).

\section{Taqman analysis of mRNA expression}

mRNA levels of CD11b, IL-10, IDO1, ARG1, NOS2, COX2, CXCR4, CXCL12/SDF-1 were analyzed in ovarian cancer-ascites infiltrating primary cells versus patient's matched PBMCs and ovarian cancer ascites-isolated CD $11 \mathrm{~b}^{+}$cells versus control CD $11 \mathrm{~b}^{+}$cells (isolated from normal blood), either after their isolation or after the overnight incubation in the presence or absence of the COX2 inhibitor Celecoxib $(20 \mu \mathrm{mol} / \mathrm{L})$, EP2 antagonist AH6809, EP4 antagonist AH23848, and EP3 antagonist L798106. The concentrations used did not have any significant impact on the viability of cultured cells, as determined by the live cell counts. Taqman analysis was done as previously described (25) on the StepOne Plus System (Applied Biosystems). The expression of each gene was normalized to HPRT1 and expressed as fold increase $\left(2^{-\Delta \mathrm{CT}}\right)$, where $\Delta \mathrm{CT}=\mathrm{CT}$ (Target gene) $-\mathrm{CT}_{(\text {HPRT1) }}$.

\section{Statistical analysis}

All data were evaluated using GraphPad Prism 5 software and analyzed using Student $t$ test ( 2 tailed), with $P<0.05$ considered as significant ( $P<0.05$ marked *; $P<0.01$ marked ${ }^{* *} ; P$ $<0.001$ marked $* * *)$. A linear correlation between 2 continuous variables was tested with the $R^{2}$ coefficient of determination. When indicated, the data from multiple different patients and control donors are expressed as means and SD from $N$ donors (see the $N$ values in the figure legends). The data from representative experiments was obtained from triplicate cultures with cells from an individual donor. Each of such independent experiments was reproduced at least 3 times.

\section{Results}

High expression of CXCR4 on cancer-isolated monocytic MDSCs mediates their attraction to CXCL12-producing ovarian cancer-infiltrating cells

CXCR4 is overexpressed on tumor-infiltrating suppressive pDCs (7), with high local levels of its ligand CXCL12 predicting reduced survival of ovarian cancer patients (26). To address the relative role of CXCL12 in MDSC accumulation, we analyzed the expression of chemokine receptors on cancer-infiltrating MDSCs and their migratory responsiveness. Bulk tumor ascites contained high numbers of $\mathrm{CD} 11 \mathrm{~b}^{+}$cells, mostly composed of monocytic MDSCs, as determined by their uniform expression of CD33 and CD34 (Refs. 10, 14; Fig. 1A). Such $\mathrm{CD} 11 \mathrm{~b}^{+} \mathrm{CD} 33^{+} \mathrm{CD} 34^{+}$MDSCs lacked expression of the costimulatory molecules 
CD80 and CD83, with most cells expressing CD14, typical of the monocytic subset of MDSCs (Refs. 10, 14, 18; Fig. 1A and Supplementary Fig. S1). These cells expressed high levels of typical MDSC-associated suppressive factors $(10,14,18)$, including arginase-1, IL-10, IDO1, IL-4Ra (CD124) and COX2 (Fig. 1B), and strongly suppressed CTL development (Fig. 1C). Such ascites-associated CD11b+ monocytic MDSCs showed uniformly high expression of CXCR4 (Fig. 1D and E), when compared with blood-isolated monocytic cells (Fig. 1E, bottom), in addition to lower levels of expression of CCR2, CCR5, and CXCR1.

In addition to the high expression of CXCR4 on isolated monocytic MDSCs (Fig. 1D and E), we observed that the numbers of MDSCs strongly correlated with the levels of CXCR4 ligand, CXCL12/SDF-1, in the tumor environment (Fig. 2A). The local gene expression of CXCL12 and secretion of CXCL12 protein was profoundly higher compared with levels in patient's blood (Fig. 2B). In contrast, CCL5/Rantes was expressed at significantly lower levels (Fig. 2C), and did not correlate with the tumor infiltration of MDSCs (data not shown). Moreover, migration of tumor-isolated MDSCs could be effectively suppressed by CXCR4 antagonist AMD3100 or by CXCL12 desensitization, but not with CCR5 antagonist vicriviroc or CCL5 desensitization (Fig. 2D). In accordance with these data, tumor-isolated MDSCs showed strong responsiveness to recombinant CXCL12 (Fig. 2E).

\section{Positive feedback between COX2 and $\mathrm{PGE}_{2}$ is responsible for both CXCR4 expression on monocytic MDSCs and the production of CXCL12 in ovarian cancer}

Guided by the reported ability of $\mathrm{PGE}_{2}$, a factor implicated in CXCR4 induction in murine cells $(23,24)$, and the production of CXCL12 in mouse tumor-associated fibroblasts (22), we tested the potential role of $\mathrm{PGE}_{2}$ in the regulation of CXCL12 production and MDSC accumulation in ovarian cancer patients. We observed a strong correlation between the expression of $\mathrm{CD} 11 \mathrm{~b}$ and $\mathrm{COX} 2$ expression (Fig. 3A) and between CXCL12 concentrations and the local production of $\mathrm{PGE}_{2}$ (Fig. 3B). In accordance with the potential causative role of $\mathrm{PGE}_{2}$ in the ovarian cancer-associated CXCL12 production, the expression and secretion of CXCL12 in ovarian cancer ascites cells was inhibited by COX2 blockade (Fig. 4A and $\mathrm{B}$ ), closely reflecting the degree of inhibition of COX2 expression and $\mathrm{PGE}_{2}$ release (Fig. $4 \mathrm{~A}$ and $\mathrm{B})$.

In accordance with the driving role of $\mathrm{PGE}_{2}$ in the CXCL12-mediated attraction of MDSCs to the tumor microenvironment, the ability of supernatants from 48 hour-cultured ovarian cancer ascites cells to attract ovarian cancer-isolated MDSCs to the ovarian cancer environment was dependent on COX2 activity and was suppressed following COX2 inhibition during the generation of the ovarian cancer cell-conditioned media (Fig. 4C). In accordance with the previous report showing that epithelial cells are the predominant source of CXCL12 in the ovarian cancer environment (7), the COX2-dependent CXCL12 expression was particularly pronounced in total ascites cells, with only marginal levels expressed in the CD11 $\mathrm{b}^{+}$fraction (Fig. 4A).

Supplementary data for this article are available at Cancer Research Online (http://cancerres.aacrjournals.org/). 


\section{Key role of $\mathrm{PGE}_{2}-\mathrm{COX2}$ feedback in the persistence of CXCR4 expression by ovarian cancer-associated monocytic MDSCs and production of CXCL12}

Interestingly, overnight COX2 inhibition reduced not only CXCL12 and CXCR4 expression in ovarian cancer ascites cells (Fig. 4A and D), but also the expression of endogenous COX2 in ovarian cancer ascites primary cells and ovarian cancer-isolated MDSCs (Fig. 4A), indicating the crucial role of an intact positive feedback loop between $\mathrm{PGE}_{2}$ and $\mathrm{COX} 2$ in the persistence of CXCR4 expression on monocytic MDSCs and the production of CXCL12 in the ovarian cancer environment. The expression of CXCR4 on ovarian cancer-isolated MDSCs was also suppressed by EP2 and EP4 (but not EP3) blockade (Fig. 4D), indicating that the effects of endogenous $\mathrm{PGE}_{2}$ on CXCR4 expression by MDSCs are mediated in part by EP2 and EP4.

\section{Discussion}

In this study, we have identified the critical role of the CXCR4-CXCL12/SDF-1 migratory axis in the accumulation of immunosuppressive monocytic MDSCs in tumor microenvironment of ovarian cancer patients. We have further showed that the tumorassociated inflammatory mediator, $\mathrm{PGE}_{2}$, induces both CXCL12/SDF-1 chemokine production in the ovarian cancer environment, and CXCR4 expression on MDSC precursors and their resulting responsiveness to CXCL12. Moreover, continued $\mathrm{PGE}_{2}$ signaling in fully developed MDSCs isolated from ovarian cancer patients is critically important for their continued expression of CXCR4 and responsiveness to CXCL12, promoting the attraction and retention of MDSCs in the tumor environment.

Correlation of ovarian cancer-associated CXCL12 levels with the local $\mathrm{PGE}_{2}$ production and local infiltration of $\mathrm{CD} 11 \mathrm{~b}^{+} \mathrm{CD} 14^{+} \mathrm{CD} 33^{+}$MDSCs substantiate the physiologic role of $\mathrm{PGE}_{2}$ in controlling monocytic MDSC accumulation in human cancer. Although the current data show that $\mathrm{PGE}_{2}$ is responsible for the induction of functional CXCR4 and CXCL12mediated attraction of MDSCs, the current results also implicate that COX2- and $\mathrm{PGE}_{2}$ antagonism may help to overcome additional CXCL12-dependent mechanism of cancer progression, that include the direct impact of CXCL12 upon tumor growth and invasiveness $(7,26)$ as well as local accumulation of CXCR4-expressing suppressive pDCs and Tregs in cancer tissues and bone-marrow of cancer patients $(7,27)$.

In line with the possibility that local $\mathrm{PGE}_{2}$ gradient in the tumor-surrounding environment allows for the gradual recruitment of migrating MDSCs or MDSC-precursors via CXCL12CXCR4, cancer cell inoculation has been shown to induce the appearance of VEGFR ${ }^{+} \mathrm{CXCR} 4^{+} \mathrm{CD} 11 \mathrm{~b}^{+}$cells in the blood of cancer-bearing mice (24). However, at present, we cannot exclude the possibility that MDSCs or MDSC-precursors are attracted into tumor microenvironment via alternative pathway and tumor-produced $\mathrm{PGE}_{2}$ induces CXCR4 expression and MDSC retention in the CXCL12-enriched tumor environment. Although tumor cells themselves or tumor-associated stromal cells (e.g., fibroblasts (22), mesothelial cells (28), and vascular endothelial cells (29) may overproduce $\mathrm{PGE}_{2}$ spontaneously (see Supplementary Fig. S2 for the variable levels of $\mathrm{PGE}_{2}$ production by the non-MDSC component of ovarian cancer ascites), an alternative possibility is that tumor 
cell-derived factors, for example mucins in the initial induction of the first wave of COX2 expression in infiltrating monocytic cells, as proposed in the colorectal cancer system (30).

Ovarian cancer-associated $\mathrm{PGE}_{2}$ promotes the MDSC expression of COX2 (Fig. 4A), the key enzyme regulating $\mathrm{PGE}_{2}$ synthesis (see Supplementary Fig. S2 for the consistently high levels of $\mathrm{PGE}_{2}$ production by ovarian cancer-isolated monocytic MDSCs), thereby creating a positive feedback loop where $\mathrm{PGE}_{2}$ produced by MDSCs helps to maintain the CXCL12 responsiveness and local retention of CXCR4 $4^{+}$MDSCs. Although this last mechanism can contribute to a vicious cycle amplifying the persistence of MDSCs within cancer settings, the requirement for continued production of $\mathrm{PGE}_{2}$ in the accumulation of MDSCs allows for new modes of their pharmacologic modulation.

Because high level of CXCL12 in ovarian cancer ascites represents a negative prognostic factor of ovarian cancer patients (26), and $\mathrm{PGE}_{2}$ also controls the production of CCL22 (25), another chemokine involved in recruiting CCR $4^{+}$Tregs and a negative prognostic factor in ovarian cancer (4), our current data highlight the key role of $\mathrm{PGE}_{2}$ in the accumulation of multiple types of cancer-associated suppressive cells $(4,7,27)$ and provide additional rationale for $\mathrm{PGE}_{2}$ targeting in ovarian cancer therapy.

In this last regard, we observed that pharmacologic inhibition of $\mathrm{PGE}_{2}$ production suppresses the production of CXCL12 in ovarian cancer ascites cells (Fig. 4A and B). Moreover, even short-term exposure of the fully developed ovarian cancer-isolated MDSCs to COX2 inhibitors (or EP2- and EP4-blockers) suppresses their expression of CXCR4 (Fig. $4 \mathrm{~A}$ and D) and migratory responsiveness to recombinant CXCL12 (Fig. 4C).

Because overproduction of $\mathrm{COX} 2$ and $\mathrm{PGE}_{2}$ is a hallmark of many tumor types (31-33), the presently defined mechanism is likely applicable to the local accumulation of MDSCs observed in different cancer types $(5,9)$. and to additional (MDSC independent) pathways of promoting tumor growth in different forms of cancer, with similarly wide therapeutic implications.

Although chemokines play a crucial role in immune and inflammatory reactions, they have an equally important role in the development of a variety of cancers, being involved in cell transformation, survival, growth, metastasis, and tumor-associated angiogenesis (34).

CXCL12 expressed by the tumor-associated fibroblasts promotes the progression of breast cancer by directly enhancing tumor growth and by recruiting endothelial progenitor cells that are required for tumor neoangiogenesis (3). $\mathrm{COX} 2$ and $\mathrm{PGE}_{2}$ are also involved in tumor stroma formation by recruiting stromal fibroblasts via the CXCL12-CXCR4 axis (22), and mediating the angiogenic effects of bFGF and VEGF by enhancing CXCR4 expression in microvascular endothelial cells (35), and by inducing proangiogenic chemokines, CXCL5 (epithelial cell-derived neutrophil activator 78), CXCL8 (IL-8) and CXCL12 (Refs. 22, 36; and the current data).

In addition to the currently shown central role of $\mathrm{PGE}_{2}$ in $\mathrm{MDSC}$ accumulation, $\mathrm{PGE}_{2}$ has recently been shown to bias the chemokine production of DCs, abrogating their CXCL9-, CXCL10-, CXCL11-, CCL5-, and CCL19-mediated ability to attract naive, effector, and memory $\mathrm{T}$ cells and $\mathrm{NK}$ cells $(25,37,38)$. Instead, $\mathrm{PGE}_{2}$ promotes the CCL22-driven 
interaction of DCs with undesirable $\mathrm{T}_{\text {reg }}$ cells (25), known to be preferentially expanded and recruited to cancer tissues (8), where the levels of CCL22 and $\mathrm{T}_{\text {reg }}$ infiltration have a strong negative prognostic value (4). The key role of $\mathrm{PGE}_{2}$ in the induction of CCL22 and CXCL12, the chemokines attracting MDSCs, $\mathrm{T}_{\text {regs }}$ and suppressive pDCs to different tumors $(4,7,8,27)$, and its ability to suppress the local influx of CTLs, Th1, and NK cells $(25,37$, 38 ), suggests the possibility of targeting $\mathrm{PGE}_{2}$ to correct the balance between the effector and suppressive cells at the tumor sites.

Overall, our current data help to understand the biology of MDSCs arising in the cancer setting, pointing to the causative role of a tumor-associated inflammatory mediator, $\mathrm{PGE}_{2}$, in one of the key aspects of monocytic MDSC biology, that is, their accumulation. They also provide rationale for including inhibitors of $\mathrm{PGE}_{2}$ synthesis and function to counteract the CXCL12-mediated immune-mediated and nonimmune mechanism of tumor progression in the therapy of cancer patients.

\section{Acknowledgments}

The authors thank Drs. Michael Shurin, Shabaana Khader, Greg Lesinski, Anda Vlad, Julie Urban, and Jeffrey Wong for their critical reading of the manuscript.

\section{Grant Support}

This work was supported by grants from NIH (1PO1 CA132714; P. Kalinski) and by a UICC American Cancer Society Beginning Investigators Fellowship funded by the ACS (N. Obermajer).

\section{References}

1. Muller A, Homey B, Soto H, Ge N, Catron D, Buchanan ME, et al. Involvement of chemokine receptors in breast cancer metastasis. Nature. 2001; 410:50-56. [PubMed: 11242036]

2. Scotton CJ, Wilson JL, Scott K, Stamp G, Wilbanks GD, Fricker S, et al. Multiple actions of the chemokine CXCL12 on epithelial tumor cells in human ovarian cancer. Cancer Res. 2002; 62:59305938. [PubMed: 12384559]

3. Orimo A, Gupta PB, Sgroi DC, Arenzana-Seisdedos F, Delaunay T, Naeem R, et al. Stromal fibroblasts present in invasive human breast carcinomas promote tumor growth and angiogenesis through elevated SDF-1/CXCL12 secretion. Cell. 2005; 121:335-348. [PubMed: 15882617]

4. Curiel TJ, Coukos G, Zou L, Alvarez X, Cheng P, Mottram P, et al. Specific recruitment of regulatory $\mathrm{T}$ cells in ovarian carcinoma fosters immune privilege and predicts reduced survival. Nat Med. 2004; 10:942-949. [PubMed: 15322536]

5. Zou W. Immunosuppressive networks in the tumour environment and their therapeutic relevance. Nat Rev Cancer. 2005; 5:263-274. [PubMed: 15776005]

6. Kryczek I, Lange A, Mottram P, Alvarez X, Cheng P, Hogan M, et al. CXCL12 and vascular endothelial growth factor synergistically induce neoangiogenesis in human ovarian cancers. Cancer Res. 2005; 65:465-472. [PubMed: 15695388]

7. Zou W, Machelon V, Coulomb-L'Hermin A, Borvak J, Nome F, Isaeva T, et al. Stromal-derived factor-1 in human tumors recruits and alters the function of plasmacytoid precursor dendritic cells. Nat Med. 2001; 7:1339-1346. [PubMed: 11726975]

8. Zou W. Regulatory T cells, tumour immunity and immunotherapy. Nat Rev Immunol. 2006; 6:295307. [PubMed: 16557261]

9. Rabinovich GA, Gabrilovich D, Sotomayor EM. Immunosuppressive strategies that are mediated by tumor cells. Annu Rev Immunol. 2007; 25:267-296. [PubMed: 17134371]

10. Gabrilovich DI, Nagaraj S. Myeloid-derived suppressor cells as regulators of the immune system. Nat Rev Immunol. 2009; 9:162-174. [PubMed: 19197294] 
11. Gabrilovich D. Mechanisms and functional significance of tumour-induced dendritic-cell defects. Nat Rev Immunol. 2004; 4:941-952. [PubMed: 15573129]

12. Gabrilovich DI, Bronte V, Chen SH, Colombo MP, Ochoa A, Ostrand-Rosenberg S, et al. The terminology issue for myeloid-derived suppressor cells. Cancer Res. 2007; 67:425. author reply 6. [PubMed: 17210725]

13. Gabrilovich DI, Corak J, Ciernik IF, Kavanaugh D, Carbone DP. Decreased antigen presentation by dendritic cells in patients with breast cancer. Clin Cancer Res. 1997; 3:483-490. [PubMed: 9815709]

14. Nagaraj S, Gabrilovich DI. Tumor escape mechanism governed by myeloid-derived suppressor cells. Cancer Res. 2008; 68:2561-2563. [PubMed: 18413722]

15. Sinha P, Clements VK, Fulton AM, Ostrand-Rosenberg S. Prostaglandin E2 promotes tumor progression by inducing myeloid-derived suppressor cells. Cancer Res. 2007; 67:4507-4513. [PubMed: 17483367]

16. Bronte V, Serafini P, Apolloni E, Zanovello P. Tumor-induced immune dysfunctions caused by myeloid suppressor cells. J Immunother. 2001; 24:431-446. [PubMed: 11759067]

17. Kusmartsev S, Gabrilovich DI. Immature myeloid cells and cancer-associated immune suppression. Cancer Immunol Immunother. 2002; 51:293-298. [PubMed: 12111117]

18. Serafini P, Borrello I, Bronte V. Myeloid suppressor cells in cancer: recruitment, phenotype, properties, and mechanisms of immune suppression. Semin Cancer Biol. 2006; 16:53-65. [PubMed: 16168663]

19. Chomarat P, Banchereau J, Davoust J, Palucka AK. IL-6 switches the differentiation of monocytes from dendritic cells to macrophages. Nat Immunol. 2000; 1:510-514. [PubMed: 11101873]

20. Gabrilovich D, Ishida T, Oyama T, Ran S, Kravtsov V, Nadaf S, et al. Vascular endothelial growth factor inhibits the development of dendritic cells and dramatically affects the differentiation of multiple hematopoietic lineages in vivo. Blood. 1998; 92:4150-4166. [PubMed: 9834220]

21. Menetrier-Caux C, Montmain G, Dieu MC, Bain C, Favrot MC, Caux C, et al. Inhibition of the differentiation of dendritic cells from CD34(+) progenitors by tumor cells: role of interleukin-6 and macrophage colony-stimulating factor. Blood. 1998; 92:4778-4791. [PubMed: 9845545]

22. Katoh H, Hosono K, Ito Y, Suzuki T, Ogawa Y, Kubo H, et al. COX-2 and prostaglandin EP3/EP4 signaling regulate the tumor stromal proangiogenic microenvironment via CXCL12-CXCR4 chemokine systems. Am J Pathol. 2010; 176:1469-1483. [PubMed: 20110411]

23. Eruslanov E, Neuberger M, Daurkin I, Perrin GQ, Algood C, Dahm P, et al. Circulating and tumorinfiltrating myeloid cell subsets in patients with bladder cancer. Int J Cancer. 2011 [Epub ahead of print].

24. Kusmartsev S, Eruslanov E, Kubler H, Tseng T, Sakai Y, Su Z, et al. Oxidative stress regulates expression of VEGFR1 in myeloid cells: link to tumor-induced immune suppression in renal cell carcinoma. J Immunol. 2008; 181:346-353. [PubMed: 18566400]

25. Muthuswamy R, Urban J, Lee JJ, Reinhart TA, Bartlett D, Kalinski P. Ability of mature dendritic cells to interact with regulatory $\mathrm{T}$ cells is imprinted during maturation. Cancer Res. 2008; 68:5972-5978. [PubMed: 18632653]

26. Kajiyama H, Shibata K, Terauchi M, Ino K, Nawa A, Kikkawa F. Involvement of SDF-1alpha/ CXCR4 axis in the enhanced peritoneal metastasis of epithelial ovarian carcinoma. Int J Cancer. 2008; 122:91-99. [PubMed: 17893878]

27. Zou L, Barnett B, Safah H, Larussa VF, Evdemon-Hogan M, Mottram P, et al. Bone marrow is a reservoir for CD4+CD25+ regulatory $\mathrm{T}$ cells that traffic through CXCL12/CXCR4 signals. Cancer Res. 2004; 64:8451-8455. [PubMed: 15548717]

28. Marrogi A, Pass HI, Khan M, Metheny-Barlow LJ, Harris CC, Gerwin BI. Human mesothelioma samples overexpress both cyclooxygenase-2 (COX-2) and inducible nitric oxide synthase (NOS2): in vitro antiproliferative effects of a COX-2 inhibitor. Cancer Res. 2000; 60:3696-3700. [PubMed: 10919635]

29. Mulligan JK, Rosenzweig SA, Young MR. Tumor secretion of VEGF induces endothelial cells to suppress T cell functions through the production of PGE2. J Immunother. 2010; 33:126-135. [PubMed: 20145550] 
30. Inaba T, Sano H, Kawahito Y, Hla T, Akita K, Toda M, et al. Induction of cyclooxygenase-2 in monocyte/macrophage by mucins secreted from colon cancer cells. Proc Natl Acad Sci U S A. 2003; 100:2736-2741. [PubMed: 12598658]

31. Zha S, Yegnasubramanian V, Nelson WG, Isaacs WB, De Marzo AM. Cyclooxygenases in cancer: progress and perspective. Cancer Lett. 2004; 215:1-20. [PubMed: 15374627]

32. Wang D, Dubois RN. Prostaglandins and cancer. Gut. 2006; 55:115-122. [PubMed: 16118353]

33. Sharma S, Stolina M, Yang SC, Baratelli F, Lin JF, Atianzar K, et al. Tumor cyclooxygenase 2dependent suppression of dendritic cell function. Clin Cancer Res. 2003; 9:961-968. [PubMed: 12631593]

34. Balkwill F. Cancer and the chemokine network. Nat Rev Cancer. 2004; 4:540-550. [PubMed: 15229479]

35. Salcedo R, Oppenheim JJ. Role of chemokines in angiogenesis: CXCL12/SDF-1 and CXCR4 interaction, a key regulator of endothelial cell responses. Microcirculation. 2003; 10:359-370. [PubMed: 12851652]

36. Pold M, Zhu LX, Sharma S, Burdick MD, Lin Y, Lee PP, et al. Cyclooxygenase-2-dependent expression of angiogenic CXC chemokines ENA-78/CXC Ligand (CXCL) 5 and interleukin-8/ CXCL8 in human non-small cell lung cancer. Cancer Res. 2004; 64:1853-1860. [PubMed: 14996749]

37. Muthuswamy R, Mueller-Berghaus J, Haberkorn U, Reinhart TA, Schadendorf D, Kalinski P. PGE2 transiently enhances DC expression of CCR7 but inhibits the ability of DCs to produce CCL19 and attract naive T cells. Blood. 2010; 116:1454-1459. [PubMed: 20498301]

38. Gustafsson K, Ingelsten M, Bergqvist L, Nystrom J, Andersson B, Karlsson-Parra A. Recruitment and activation of natural killer cells in vitro by a human dendritic cell vaccine. Cancer Res. 2008; 68:5965-5971. [PubMed: 18632652]

39. Kusmartsev SA, Li Y, Chen SH. Gr-1+ myeloid cells derived from tumor-bearing mice inhibit primary T cell activation induced through CD3/CD28 costimulation. J Immunol. 2000; 165:779785. [PubMed: 10878351] 
A
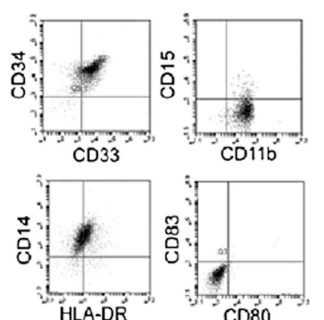

D

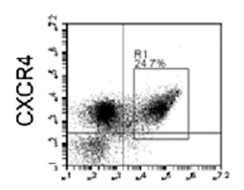

CD11b

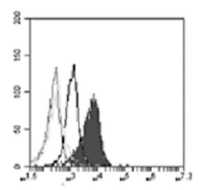

CXCR4
B $\quad$ C

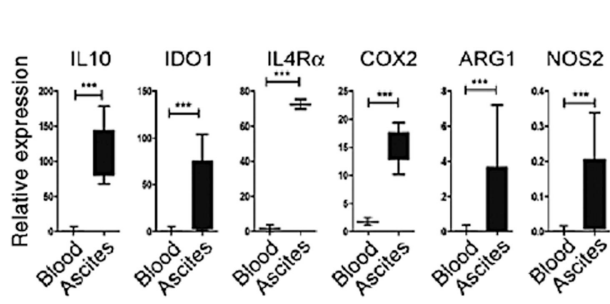

$(-)$

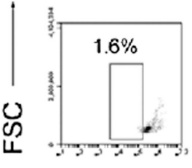

$\mathrm{CD} 3 / \mathrm{CD} 28$

$\mathrm{CD} 3 / \mathrm{CD} 28+\mathrm{CD} 3 / \mathrm{CD} 28+$ prim. cancer cells CD11b* cells
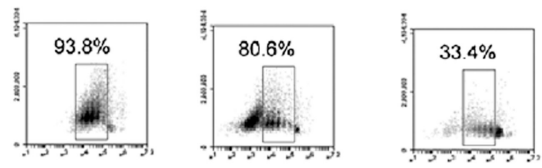

CFSE

E
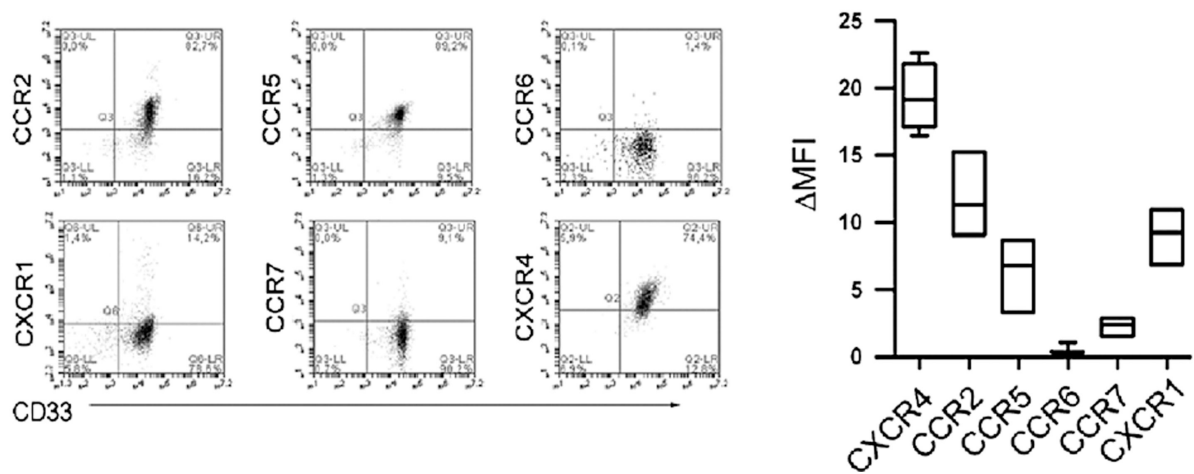

Figure 1.

CXCR4-CXCL12-mediated accumulation of monocytic MDSCs. MDSC-associated phenotype and functions of ovarian cancer ascites-isolated $\mathrm{CD} 11 \mathrm{~b}^{+}$cells. A, characterization of ovarian cancer-isolated $\mathrm{CD} 11 \mathrm{~b}^{+} \mathrm{CD} 14^{+} \mathrm{CD} 15^{-} \mathrm{CD} 33^{+} \mathrm{CD} 34^{+} \mathrm{HLADR}^{\text {low }} \mathrm{CD} 80^{-} \mathrm{CD} 83^{-}$ cells. High percentage of CD11 $\mathrm{b}^{+}$cells $(8.9 \%-50.0 \%$, mean $24.2 \%, N=7)$ was present within the ascites total primary cell population. B, relative expression of IL10, ARG1, IDO1, IL4Ra, CXCR4, and COX2, in control and ovarian cancer-isolated CD11b ${ }^{+}$cells $(N=7$, ovarian cancer ascites-isolated; $N=5$, blood-isolated, control). Histograms present data of a single representative experiment with different donors as mean $\pm \mathrm{SD}$. C, suppression of CFSE-labeled allogeneic naive $\mathrm{CD}^{+}{ }^{+} \mathrm{T}$-cell proliferation (CD3/CD28 stimulation; ref. 39) in the presence or absence of ovarian cancer-infiltrating primary cells or ovarian cancerisolated monocytic MDSCs $(N=7)$. Percentages indicate the fraction of proliferating $\mathrm{CD}^{+}$ cells. The gray squares represent the lymphocyte-specific gates, used to exclude (CFSE-

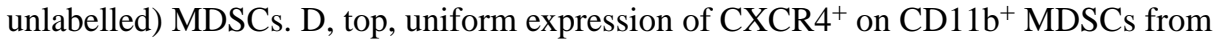
ovarian cancer ascites. D, bottom, CXCR4 is elevated on cancer-isolated CD $11 b^{+}$monocytic cells (filled histogram) compared with control blood-isolated CD11 ${ }^{+}$monocytic cells (unfilled, thick line). B, CXCR4 expression in ovarian cancer-isolated MDSCs

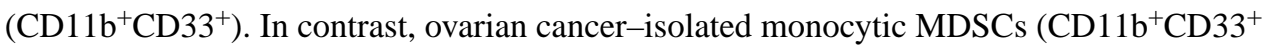
cells) lack the expression of CCR6 and CCR7 receptors. B, left, representative data from 1 of 7 different cancer patients is shown. B, right, cumulative data from 7 different cancer patients, expressed as mean $\pm \mathrm{SD}$. *, $P<0.05 ; * *, P<0.01 ; * * *, P<0.001$. 
A

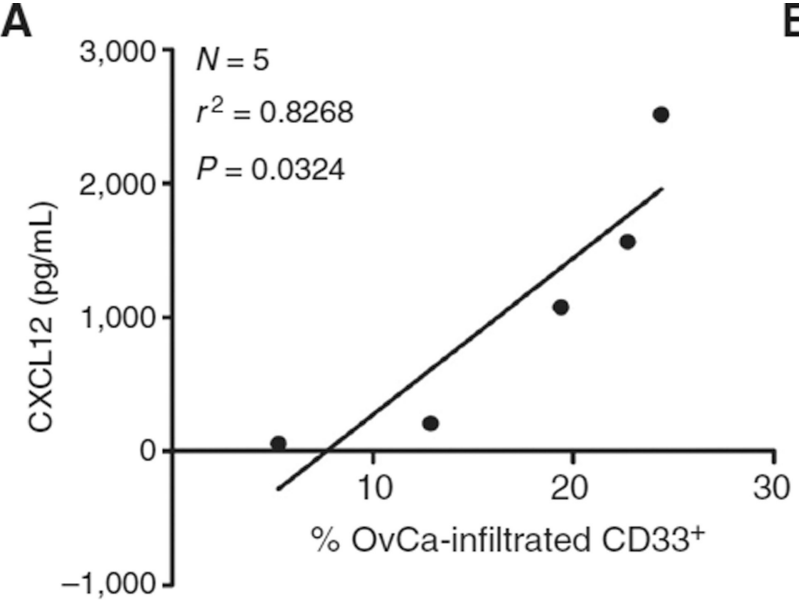

B

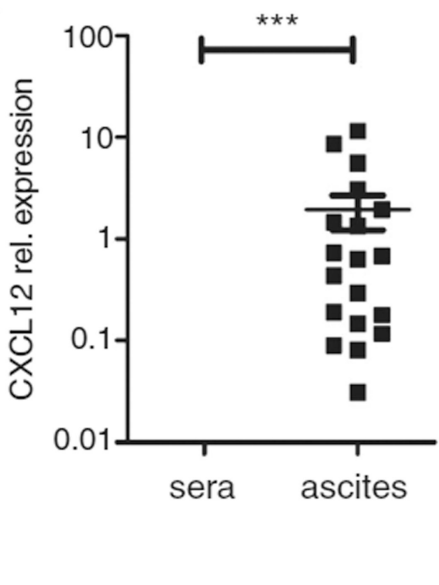

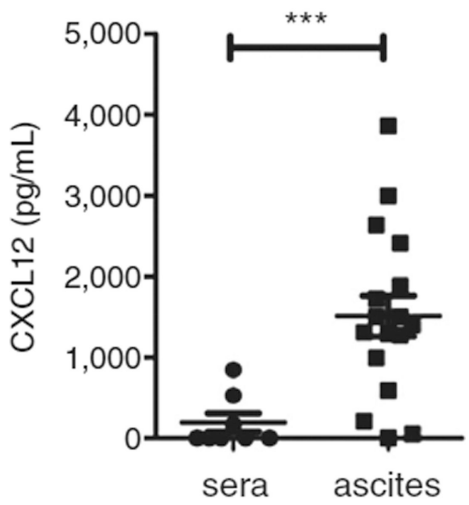
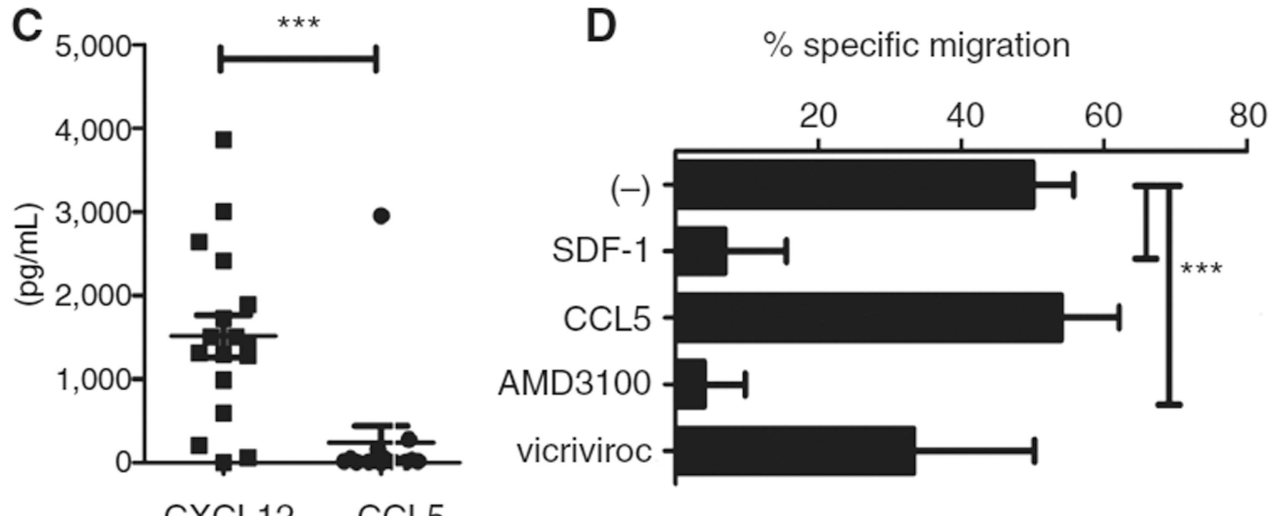

$\mathbf{E}$

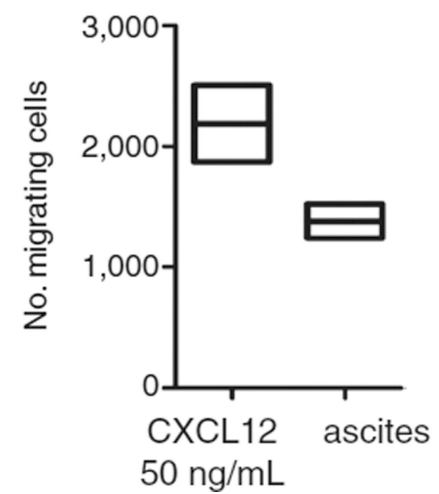

Figure 2.

CXCL12-driven accumulation of cancer-associated monocytic MDSCs. A, correlation between CXCL12 levels and frequency of $\mathrm{CD} 11 \mathrm{~b}^{+} \mathrm{CD} 33^{+}$cells in ovarian cancer ascites from different patients. The percentage of $\mathrm{CD} 11 \mathrm{~b}^{+} \mathrm{CD} 33^{+}$cells in ovarian cancer ascites was determined by flow cytometry analysis after staining of ovarian cancer ascites-infiltrating primary cells, harvested from fresh ascites by centrifugation ( $N=5$ patients). The regression line and corresponding $r^{2}$ value is shown. OvCa, ovarian cancer. B, CXCL12 expression (left; $N=19$; vs. $N=5$ ) and protein levels (right; $N=17 ; 1509 \mathrm{pg} / \mathrm{mL}$ vs. $N=8 ; 193 \mathrm{pg} / \mathrm{mL}$ ) in ovarian cancer ascites from different patients compared with cancer patient sera. $\mathrm{C}$, CXCL12 versus CCL5 levels in ovarian cancer ascites from 17 different patients. D, specific migration of ovarian cancer-isolated MDSCs to ascites in the absence or presence of CXCR4 antagonist AMD3100, CCR5 antagonist vicriviroc, or CXCL12 and CCL5 desensitized. E, responsiveness of ovarian cancer-isolated MDSCs to rhCXCL12 (50 $\mathrm{ng} / \mathrm{mL}$ ) and ovarian cancer ascites. All data (A-E) were confirmed in 3 to 7 independent experiments. The bars represent cumulative data from 3 to 7 different donors, expressed as mean \pm SD. *,$P<0.05 ; * *, P<0.01 ; * * *, P<0.001$. 


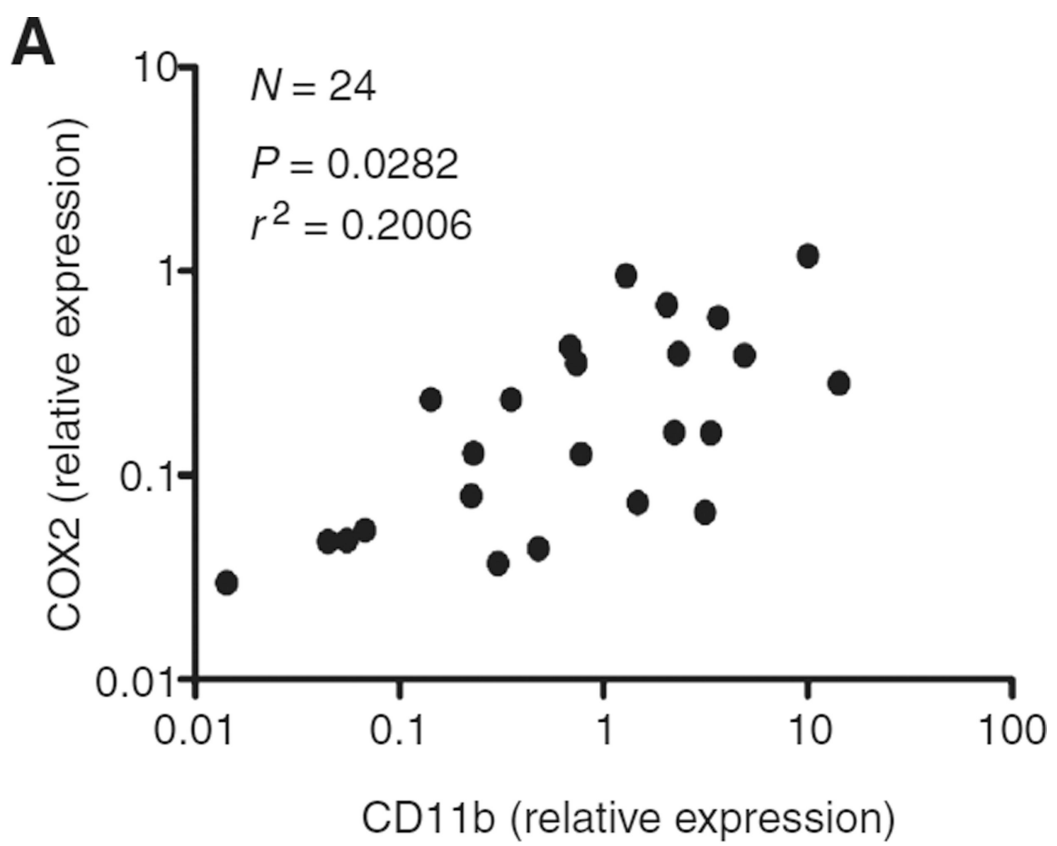

B

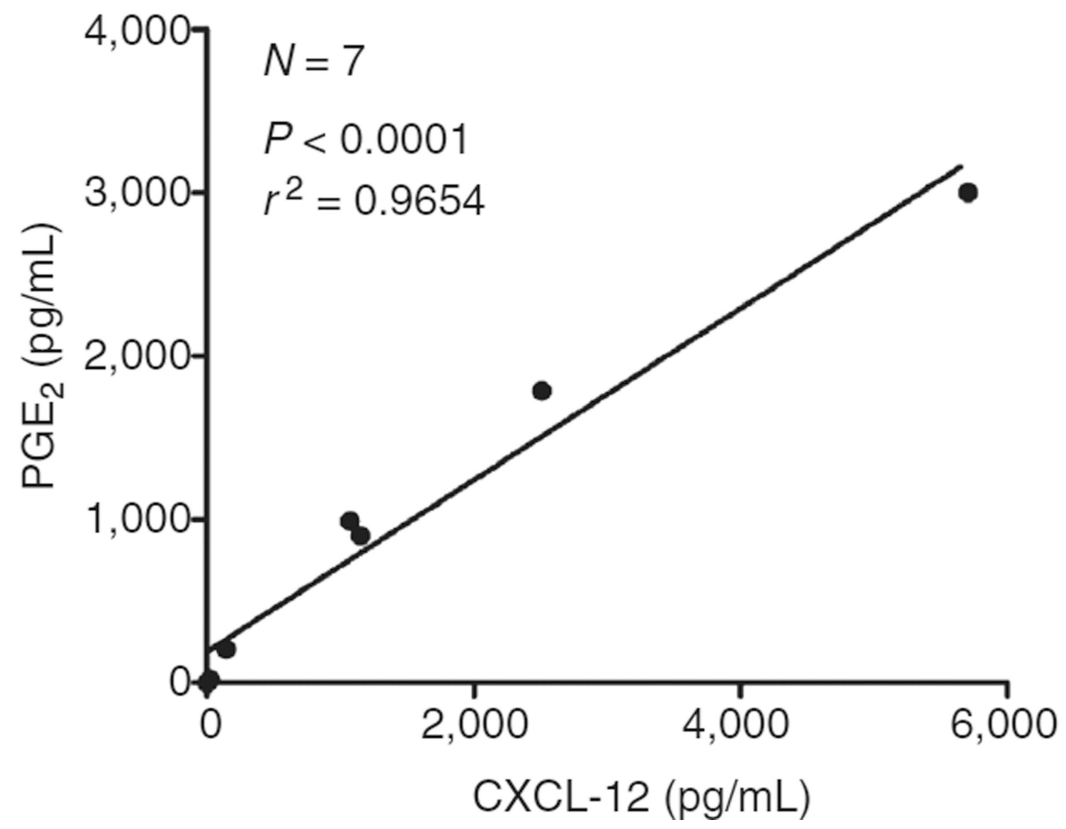

Figure 3.

COX2/ $\mathrm{PGE}_{2}$ correlate with accumulation of cancer-associated monocytic MDSCs. A, correlation between CD11b (denoting the numbers of MDSCs) and COX2 relative expressions in cells isolated from ovarian cancer patients $(N=24)$. The regression line and corresponding $r^{2}$ value is shown. B, correlation between PGE 2 levels and SDF-1/CXCL12 concentrations produced in cancer environment ( $N=7$ patients). The regression line and corresponding $I^{2}$ value are shown. 


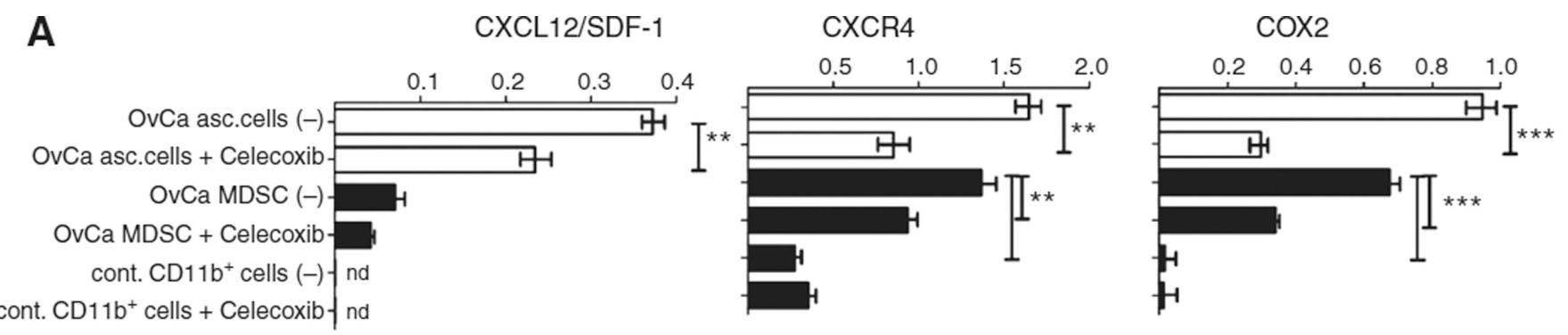

B

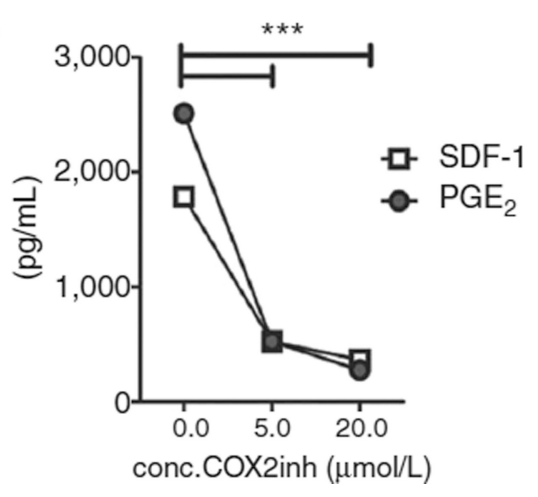

C

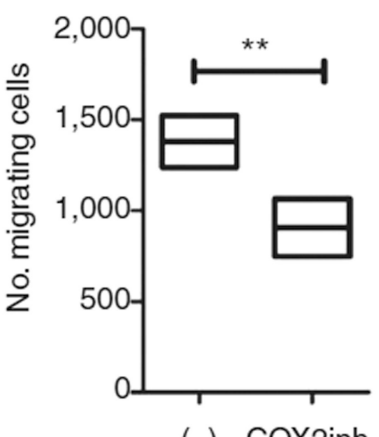

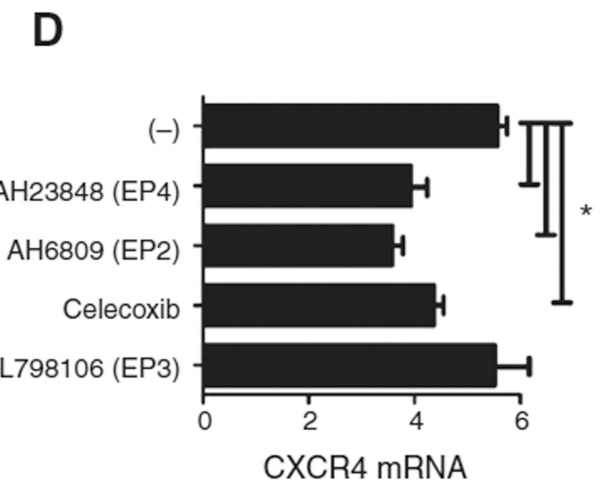

Figure 4.

$\mathrm{COX} 2 / \mathrm{PGE}_{2}$ feedback in the cancer environment is responsible for the induction of

CXCL12-driven accumulation of cancer-associated monocytic MDSCs. A, relative expression of COX2, CXCR4, and CXCL12 in ovarian cancer-infiltrating primary cells (white bars) and ovarian cancer-isolated $\mathrm{CD} 11 \mathrm{~b}^{+}$cells (black bars), compared with control blood-isolated $\mathrm{CD} 11 \mathrm{~b}^{+}$cells, pretreated or not with Celecoxib (n.d., not detectable). OvCa, ovarian cancer. $\mathrm{B}, \mathrm{CXCL} 12$ and $\mathrm{PGE}_{2}$ protein levels in ovarian cancer-infiltrating primary cell-conditioned media, obtained in the presence or absence of the COX2 inhibitor celecoxib. C, migratory responsiveness to ovarian cancer ascites in ovarian cancer-isolated MDSCs pretreated or not with COX2 inhibitor (Celecoxib, $20 \mathrm{mmol} / \mathrm{L}$ ). D, relative expression of CXCR4 in ovarian cancer-isolated CD11 b ${ }^{+}$cells, pretreated or not with Celecoxib, EP4 antagonist AH23848, EP2 antagonist AH6809, and EP3 antagonist L798106. All data (A-D) were reproduced in 3 to 7 independent experiments, using the cells from different donors. The individual bars represent cumulative data from all donors, expressed as mean $\pm \mathrm{SD}$. * $P<0.05 ; * *, P<0.01 ; * * *, P<0.001$. 